\title{
Prevalence of Stroke, Coronary Artery Disease, Arrhythmias and Heart Failure: A Community-Based Study in Northern Cameroon
}

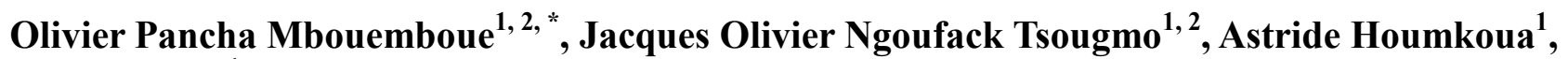 \\ Daouda Alim ${ }^{1}$
}

${ }^{1}$ Department of Biomedical Sciences, Faculty of Science, University of Ngaoundere, Ngaoundere, Cameroon

${ }^{2}$ Ngaoundere Regional Hospital, Ngaoundere, Cameroon

\author{
Email address: \\ olivier_pancha@yahoo.fr (O. P. Mbouemboue),ngoufacktsougmo@yahoo.fr (J. O. N. Tsougmo), \\ houmkouastre@gmail.com (A. Houmkoua), daouda.alim@yahoo.fr (D. Alim) \\ ${ }^{*}$ Corresponding author
}

\section{To cite this article:}

Olivier Pancha Mbouemboue, Jacques Olivier Ngoufack Tsougmo, Astride Houmkoua, Daouda Alim. Prevalence of Stroke, Coronary Artery Disease, Arrhythmias and Heart Failure: A Community-Based Study in Northern Cameroon. Cardiology and Cardiovascular Research. Vol. 5, No. 2, 2021, pp. 120-124. doi: 10.11648/j.ccr.20210502.19

Received: May 4, 2021; Accepted: June 3, 2021; Published: June 16, 2021

\begin{abstract}
Data on the cardiovascular disease epidemiology in Northern Cameroon remain insufficient. This study aimed at assessing the prevalence of stroke, coronary artery disease (CAD), arrhythmias and heart failure among the Ngaoundere population. This was a community-based study conducted in Ngaoundere from March to June 2018. The study population consisted of adults over 20 years' old who had been living in the city of Ngaoundere for at least one year and who had consented to participate in the study. Data was collected using a structured questionnaire. The questionnaire included sociodemographic (gender, age, occupation, education, marital status, cardiovascular risk factors, personal and family history of CVD), and physical examination. Stroke, CAD, arrhythmias and heart failure were established by a combination of self reporting and the judgment of a cardiologist coauthor according to a physical examination. In total, 948 subjects aged 20 to 89 were included in the study. Their mean age was $39.92 \pm 14.75$ years. The prevalence of stroke, CAD, arrhythmias and heart failure were $0.74 \%, 3.06 \%, 3.6 \%$, and $12.45 \%$ respectively in the study population. In conclusion, in this area, prevalence of stroke, arrhythmias and heart failure was high among adult population. However, further studies including instrumental methods of cardiovascular diagnosis are needed to determine trends of CVD's prevalence in Ngaoundere locality.
\end{abstract}

Keywords: Stroke, Coronary Artery Disease, Arrhythmias, Heart Failure, Prevalence, North Cameroon

\section{Introduction}

Cardiovascular diseases (CVDs) are the leading cause of death and disability worldwide $[1,2]$. They are responsible for approximately one third of global mortality. Otherwise, more than three-quarters of deaths from CVDs occur in low and middle-income countries. Current evidence suggests that CVDs are taking on endemic proportion in Africa and are on a drawn of epidemiological transition through which cardiovascular health will probably become in a few years the first public health priority on this continent. Available projections suggest that in a few decades, CVDs and others non communicable diseases will overtake communicable diseases as the most frequent cause of death in this region particularly due to stroke and coronary artery disease (CAD) $[3,4]$.

At the same time, while the prevalence and mortality due to CVDs is increasing in Sub-Saharan Africa (SSA), they burden varies with geographic regions [5]. In Cameroon with a few exceptions, studies on the epidemiology of CVDs are scarce in the northern regions. At the same time, in these regions health care facilities are recording more and more CVDs at various stage of their development. Most of them certainly remain undiagnosed due to insufficient resources and poverty. The aim of the present study was to investigate 
the prevalence of four main CVDs (Stroke, CAD, arrhythmias and heart failure) in the Ngaoundere area in Northern Cameroon.

\section{Material and Methods}

\subsection{Study Design and Setting}

The study was a community-based, cross-sectional study conducted from March to June 2018 in Ngaoundere, Cameroon.

\subsection{Study Population}

The study involved the population of the city of Ngaoundere estimated at 158,348 inhabitants according to the Third General Population and Housing Census [6]. People aged 20 years and over representing $44.8 \%$ of the population, the size of the source population was therefore estimated at 70,940 inhabitants.

The sample size was calculated according to the formula $\mathrm{N}=\mathrm{P}(1-\mathrm{P})(\mathrm{Z} / \mathrm{e}) 2$ (55); with $\mathrm{N}=$ sample size, $\mathrm{P}=$ target proportion of cardiovascular disease $(50 \%$ for this study), $\mathrm{Z}=\mathrm{Z5} \%=1.96$ and $\mathrm{e}=$ margin of error $=5 \%$ for this work. According to this formula, the sample size obtained was $\mathrm{N}=385$ subjects. To reduce the effect of the sample design, we multiplied this size by two to obtain 770 subjects and, taking into account the imponderables, we maximized this figure by $35 \%$, obtaining a total of 948 people to be interviewed.

Adults over 20 years of age, residing in the city of Ngaoundere for at least one year, and having consented to participate in the study, were included.

\subsection{Data Collection}

Data were obtained using a structured questionnaire. The questionnaire included socio-demographic (gender, age, occupation, education, marital status, cardiovascular risk factors, personal and family history of CVD), and physical examination. Stroke, CAD, arrhythmias and heart failure were established by a combination of self reporting and the judgment of a cardiologist coauthor according to a physical examination.

\subsection{Operational Definitions}

In this study, stroke was identified by the presence of a focal neurological deficit lasting one month or less, or a yes answer to the question "Have you ever been told by a physician after examination that you suffered a stroke?".

CAD (angina pectoris or myocardial infarction) was established in our study by self-reported history of hospitalization for angina pectoris, myocardial infarction or a yes answer to the question "Has a physician told you in recent weeks that you are suffering from angina pectoris or myocardial infarction?

Cardiac arrhythmias were defined as any complaint of transient, sustained or episodic palpitations that have been present for at least one month.

Heart failure was defined in our study as the presence of New York Heart Association II to IV stage dyspnea for at least one month and associated with a sign of peripheral congestion or a yes answer to the question "Have you been diagnosed with heart failure by a physician?»

Anthropometric characteristics and blood pressure were defined and measured as described in a previous study [7].

\subsection{Data Analysis}

The data was entered into an electronic form created using Microsoft Excel 2013® software to form a database. This software also helped to carry out a quality control of the data. The data were analyzed using SPSS 20.0® software. The statistical methods used were the calculation of population and proportions for qualitative variables and the calculation of mean and standard deviations for quantitative variables.

\subsection{Ethical Consideration}

The authorization to carry out this survey was obtained from the Adamawa delegation of public health (Ref. $\mathrm{N}^{\circ}$ 1050/L/HN/DRSPA/SAGE/BPF/NGD). The study protocol was approved by the Ethic committee of the Ngaoundere Regional Hospital (Ref. $\mathrm{N}^{\circ}$ 4540/AR/MINSANTE/HRN/CM), and an informed consent (verbal or written) was obtained from all participants.

\section{Results}

A total of 948 subjects aged 20 to 89 were included into the study. The average age of the participants was $39.92 \pm 14.75$ years, with 20 to 39 years as the most represented age group. The proportion of women was higher than men (sex ratio 1.04). Baseline characteristic of the study population is presented in detail in Table 1.

Informal sector workers and housewives were the most numerous $(33.44 \%$ and $32.59 \%)$. In terms of educational attainment, participants with secondary education were the highest in number $(33.65 \%)$, followed by those with a purely Koranic education (24.05\%). Furthermore, the majority of participants were married (61.71\%). Regarding anthropometric parameters, the prevalence of overweight and obesity were $27 \%$ and $12.55 \%$ respectively. In addition, $46.94 \%$ and $5.59 \%$ of study population presented with high blood pressure (HBP) and diabetes.

Overall 7 subjects $(0.74 \%)$ had stroke, all with reported history of stroke. the prevalence of CAD, arrhythmias and heart failure were respectively $3.06 \%, 3.6 \%$ and $12.45 \%$. Women reported significantly higher prevalence than men for arrhythmias $(5.17$ v. $1.94, \mathrm{p}<0.05)$ and heart failure $(17.77$ v $6.90 \mathrm{p}<0.01)$. CAD, arrhythmias and heart failure were associated with history of heart failure $(p<0.01)$ and history of CAD $(p<0.01)$, while heart failure was associated with family history of HPB $(\mathrm{p}<0.01)$, diabetes mellitus $(\mathrm{p}<0$. $01)$ and HBP $(p<0.05)$. (Table 2$)$ 
Table 1. General characteristics of the study population.

\begin{tabular}{|c|c|c|}
\hline Parameters & $\mathbf{N}$ & $\%$ \\
\hline \multicolumn{3}{|l|}{ Gender } \\
\hline Men & 464 & 48.95 \\
\hline Women & 484 & 51.05 \\
\hline \multicolumn{3}{|l|}{ Age (years) } \\
\hline $20-39$ & 572 & 60.34 \\
\hline $40-64$ & 301 & 31.80 \\
\hline 65 et plus & 75 & 7.91 \\
\hline \multicolumn{3}{|l|}{ Occupation } \\
\hline Civil servants & 132 & 13.92 \\
\hline Traders & 91 & 9.60 \\
\hline Housewives & 317 & 33.44 \\
\hline Informal workers & 309 & 32.59 \\
\hline Others & 99 & 10.44 \\
\hline \multicolumn{3}{|l|}{ Education level } \\
\hline Had not been at school & 74 & 11.16 \\
\hline Primary level & 221 & 23.31 \\
\hline Secondary level & 319 & 33.65 \\
\hline Higher level & 106 & 11.18 \\
\hline Only koranic & 228 & 24.05 \\
\hline \multicolumn{3}{|l|}{ Marital status } \\
\hline Singles & 276 & 29.11 \\
\hline Married & 585 & 61.71 \\
\hline Divorced & 51 & 5.38 \\
\hline Widows & 36 & 3.80 \\
\hline \multicolumn{3}{|l|}{ Religion } \\
\hline Christians & 436 & 45.99 \\
\hline Muslims & 508 & 53.59 \\
\hline Others & 4 & 0.42 \\
\hline \multicolumn{3}{|l|}{ Cardiovascular disease risk factors } \\
\hline Family history of HBP & 318 & 33.54 \\
\hline Family history of DM & 179 & 18.88 \\
\hline Family history of stroke & 56 & 5.90 \\
\hline Family history of HF & 163 & 17.19 \\
\hline Family history of CAD & 40 & 4.21 \\
\hline Overweight & 256 & 27.00 \\
\hline Obesity & 119 & 12.55 \\
\hline $\mathrm{HBP}$ & 445 & 46.94 \\
\hline Diabetes & 53 & 5.59 \\
\hline
\end{tabular}

CAD: Coronary artery disease. Diabetes mellitus. HF: Heart failure. HBP: High blood pressure.

Table 2. Frequency of cardiovascular diseases according to general characteristics of the study population.

\begin{tabular}{|c|c|c|c|c|c|}
\hline \multirow{2}{*}{ Parameters } & Total & Stroke & CAD & Arrhythmias & Heart failure \\
\hline & $\mathbf{N}(\%)$ & $\mathbf{N}(\%)$ & $\mathbf{N}(\%)$ & $\mathbf{N}(\%)$ & $\mathbf{N}(\%)$ \\
\hline \multicolumn{6}{|l|}{ Gender } \\
\hline Men & $464(48.95)$ & $1(0.22)$ & $8(1.72)$ & $9(1.94)^{*}$ & $32(6.90)^{* *}$ \\
\hline Women & $484(51.05)$ & $6(1.24)$ & $21(4.34)$ & $25(5.17)$ & $86(17.77)$ \\
\hline Total & 948 & $7(0.74)$ & $29(3.06)$ & $34(3.6)$ & $118(12.45)$ \\
\hline \multicolumn{6}{|l|}{ Age (years) } \\
\hline $20-39$ & $572(60.34)$ & $4(0.70)$ & $15(2.62)$ & $19(3.32)$ & $67(11.71)$ \\
\hline 65 et plus & $75(7.91)$ & $0(0.00)$ & $1(1.33)$ & $2(2.67)$ & $14(18.67)$ \\
\hline \multicolumn{6}{|l|}{ Occupation } \\
\hline Civil servants & $132(13.92)$ & $0(0.00)$ & $2(1.52)$ & $4(0.03)^{*}$ & $17(12.88)^{* *}$ \\
\hline Traders & $91(9.60)$ & $2(2.20)$ & $1(1.10)$ & $1(1.10)$ & $12(13.19)$ \\
\hline Housewives & $317(33.44)$ & $3(0.97)$ & $18(5.83)$ & $9(33.44)$ & $28(8.83)$ \\
\hline Informal workers & 309 (32.59) & $2(0.63)$ & $8(2.52)$ & $20(6.47)$ & $58(18.77)$ \\
\hline Others & $99(10.44)$ & $0(0.00)$ & $0(0.00)$ & $0(0.00)$ & $3(3.03)$ \\
\hline Had not been at school & $74(11.16)$ & $0(75.00)$ & $6(8.11)$ & $6(8.11)$ & $2(2.70)^{* *}$ \\
\hline Primary level & $221(23.31)$ & $2(0.90)$ & $6(2.71)$ & $6(2.71)$ & $34(15.38)$ \\
\hline Secondary level & $319(33.65)$ & $3(0.94)$ & $8(2.51)$ & $11(3.45)$ & $37(11.60)$ \\
\hline Higher level & $106(11.18)$ & $0(0.00)$ & $1(0.74)$ & $1(0.94)$ & $4(3.77)$ \\
\hline Only koranic & $228(24.05)$ & $2(0.88)$ & $8(3.51)$ & $10(4.39)$ & $41(17.98)$ \\
\hline
\end{tabular}


Table 2. Continued.

\begin{tabular}{|c|c|c|c|c|c|}
\hline \multirow{2}{*}{ Parameters } & Total & Stroke & CAD & Arrhythmias & Heart failure \\
\hline & $\mathbf{N}(\%)$ & $\mathbf{N}(\%)$ & $\mathbf{N}(\%)$ & $\mathbf{N}(\%)$ & $\mathbf{N}(\%)$ \\
\hline \multicolumn{6}{|l|}{ Marital status } \\
\hline Singles & $276(29.11)$ & $2(0.72)$ & $1(0.36)^{*}$ & $3(1.09)^{*}$ & $19(68.88)^{* *}$ \\
\hline Married & $585(61.71)$ & $4(0.68)$ & $22(3.67)$ & $24(4.16)$ & $84(14.38)$ \\
\hline Divorced & $51(5.38)$ & $0(0.00)$ & $4(7.84)$ & $4(7.84)$ & $5(9.80)$ \\
\hline Widows & $36(3.80)$ & $1(2.70)$ & $2(5.41)$ & $3(8.11)$ & $10(27.03)$ \\
\hline Others & $4(0.42)$ & & & & \\
\hline \multicolumn{6}{|l|}{ CVRFs } \\
\hline Family history of HBP & $318(33.54)$ & $6(1.89)$ & $10(3.14)$ & $12(3.77)$ & $53(16.67)^{* *}$ \\
\hline Family history of DM & $179(18.88)$ & $4(2.23)$ & $8(4.47)$ & $9(5.03)$ & $34(18.99)^{* *}$ \\
\hline Family history of stroke & $56(5.90)$ & $7(12.50)$ & $1(1.79)$ & $1(1.79)$ & $6(10.71)$ \\
\hline Family history of HF & $163(17.19)$ & $0(0.00)$ & $21(12.88)^{* *}$ & $21(12.88)^{* *}$ & $39(23.93)^{* *}$ \\
\hline Family history of CAD & $40(4.21)$ & $0(0.00)$ & $29(75.50)^{* *}$ & $29(72.50)^{* *}$ & $16(40.00)^{* *}$ \\
\hline Overweight & $256(27.00)$ & $2(0.78)$ & $5(1.75)$ & $7(2.73)$ & $32(12.50)$ \\
\hline Obesity & $119(12.55)$ & $0(0.00)$ & $5(4.20)$ & $6(5.04)$ & $21(17.65)$ \\
\hline HBP & $445(46.94)$ & $4(0.90)$ & $13(2.92)$ & $15(3.37)$ & $51(10.14)^{*}$ \\
\hline Diabetes & $53(5.59)$ & $1(1.89)$ & $2(3.77)$ & $2(3.77)$ & $10(18.87)$ \\
\hline
\end{tabular}

$* \mathrm{p}<0.05, * * \mathrm{p}<0.01$. CAD: Coronary artery disease. Diabetes mellitus. HF: Heart failure. HBP: High blood pressure. CVRFs: Cardiovascular disease risk factors.

\section{Discussion}

This study aimed at reporting the prevalence of stroke, arrhythmias, coronary artery disease and heart failure among the Ngaoundere population in Cameroon. The prevalence of CVDs nears $20 \%$ of the adult population in this area.

The results revealed that the overall prevalence of stroke was $0.74 \%$ in the study population.

This was lower than in Ghana (2.8\%), Russian Federation (6.1\%), India (2\%) and the United States $(1.2 \%)[8,9]$, but higher than the one reported in hospital setting $(0.5 \%)$ in Ngaoundere [10].

This study also showed more stroke cases among females than males, which is in accordance with two hospital based studies conducted in Palestine [11, 12]. However, our result differs from those of Sagui et al and Komolafe et al who reported a masculine predominance of stroke in studies carried out in Sub-Saharan African setting [13, 14].

The overall prevalence of CAD was $3.06 \%$. As compared to western and Indian data $[15,16]$ the prevalence rate of CAD was lower in our study. These findings are suggestive of relatively low prevalence of $\mathrm{CAD}$ in our region compared to that reported in more economically developed countries than ours. Although, this situation may rapidly change due to, urbanization, and increasing rise of the prevalence of CVD risk factors and the alarming low level of awareness of these risk factors in the Ngaoundere locality [17]. In previous studies we showed that awareness of hypertension, diabetes and dyslipidemias was poor in our locality, and even among the aware, control were suboptimal $[17,18]$.

The prevalence rate of CAD was higher in women than in men (4.34 v. 1.72). Our results are consistent with findings of a study by Ye Ruan et al in which women were more likely to have angina than men [8].

Usually Arrhythmias are defined as disorders of electrical properties of the heart, or abnormalities in the rate, rhythm or both of the heart beat $[19,20]$. Arrhythmias were defined in this study as the presence of palpitation among participants. This criterion is not sufficient to define a cardiac rhythm disorder in clinical practice [21]. According to Giada and Raviele [22], a good history, physical examination and an electrocardiogram can determine the majority of cardiac causes of arrhythmias in people complaining of palpitations. Nevertheless, the prevalence of arrhythmias as established in this study was high in the population (3.6\%). Use of a resting electrocardiogram (ECG), or ECG rhythm monitoring in the investigation could have clarified the nature of these conditions and permit the estimation of the frequency of those that did not manifest themselves as palpitations.

Regarding heart failure, the prevalence of this condition in Sub-Saharan African setting remains largely unexplored in the general population. Most of the epidemiological data on heart failure in our setting are derived from hospital-based studies. Data from these studies depicted a prevalence rate of heart failure at a little over $30 \%$ in cardiology settings and $3 \%$ to $7 \%$ in general medical services [23-26] In our study population the prevalence of heart failure was $12.45 \%$. The operational definition of heart failure chosen did not take into account radiographic and echocardiographic criteria. This could have contributed to an over-estimation of the prevalence of this condition found in the study population.

\section{Conclusion}

The prevalence of recent stroke, CAD, arrhythmias and heart failure were $0.74 \%, 3.06 \%, 3.6 \%$ and $12.45 \%$ respectively in our environment. The limitations of our study were as follow: i) data was based on self-reports, which probably lead to recall bias; ii) the cross sectional nature of the study was another important limitation.

Further studies with more stringent diagnosis criteria and more intensive data analysis are needed to determine trends of CVD prevalence in our area. 


\section{Conflict of Interest}

The authors declare that they have no competing interests.

\section{References}

[1] World Heart Organization Geneva: Preventing Chronic Diseases: A Vital Investment 2005.

[2] Movsisyan NK, Vinciguera M, Medina Inojosa JR, and Lopez-Jimenez F. Cardiovascular disease in central and eastern europe; a call for more surveillance and evidence based health promotion. Annals of Global Health, 2020; 86 (1) 21.

[3] Yuyun FM, Sliwa K, Kengne AP, Mocumbi AO, Bukhman G. Cardiovascular diseases in Sub-Saharan Africa compare to high income countries Glo Heart 2020; 292: 15 (1): 15.

[4] Mathers CD, Loncar D, Projections of global mortality and burden of disease from 2002 to 2030 PLoS medecine. 311: e442 s.

[5] Roth AG, Johnson C, Abajobir A, Abd Allah F, Abera SF, Abyu et al. Global, regional, and national burden of cardiovascular Diseases for 10 causes, 1990 to 2015. J Am Coll Cardiol. 2017; 70: (1) 1-25).

[6] Institut National de la Statistique (INS) and ICF International, Cameroon Demographic and Health Survey and Multiple Indicator Cluster Survey 2011. Calverton, Maryland, USA: INS and ICF International 2012.

[7] Pancha Mbouemboue O, Derew D, Tsougmo, Ngoufack JO, Tangyi Tamanji M; A Community-Based Assessment of Hypertension and some Other Cardiovascular Disease Risk Factors in Ngaoundere, Cameroon; International Journal of Hypertension; 2016: http://dx.doi.org/10.1155/2016/4754636.

[8] Ruan Y, Guo Y, Zhen Y, Huang Z, Sun S, Kowal P et al. Cardiovascular disease and associated risk factors among older adults in six low and middle income countries: results from SAGE Wave 1. BMC Public Health 2018; 18: 778.

[9] Mozaffarian DB, Benjamin E, Go AS, Arnett DK, Blaha MJ, Cushman M. Heart disease and stroke statistics-2015 Update: A Report from the American Heart Association. Circulation 2015; 133 (4): e38-360.

[10] Pancha MO, Ngoufack JO, KoonaKoona A, Maha F, Kingue S. Place and Evolutionary Profile of Cardiovascular Diseases in the Northern Cameroonian Hospital Environment: The Case of the Regional Hospital of Ngaoundere. Health Sci Dis. 2015; $16(1), 1-7$.

[11] Sweileh WM, Sawalha AF, Al -Aquad SM, Zyoud SH, Al Jabi SW. The epidemiology of stroke in Northern Palestine: A one year, Hospital based study. J Stroke Cerebrovascular Dis Nov, 175 (6): 406-11.
[12] Sawalha AF. Characterization of hospitalized ischemic stroke patients in Palestine. Lybian J Med [Internet] 2009; 4 (2).

[13] Sagui E, M'baye PS, Dubecq C, Khadi Fall KB, Niang A, Gning $\mathrm{S}$ et al. Ischemic and Hemorrhagic Strokes in Dakar, Senegal: A hospital based study. Stroke 2005; 36, 1844-1847.

[14] Komolafe MA, Komolafe EO, Fatoye, Adetiloye V, Asaleye $\mathrm{C}$, Famurewa $\mathrm{O}$ et al. Profil of Stroke In Nigerians; A Prospective Clinical Study. African Journal of Neurogical Sciences, 2007; 27, 360-365.

[15] Menotti A, Puddu PE, Coronary heart disease differences across Europe: a contribution from the seven countries study. J Cardiovasc Med (Hagerstown) 2013; 14 (11): 767-72.

[16] Krishnan MN, Coronary heart Disease and risk factors in India - On the brink of an epidemic. Indian Heart J 2012; 64 (4): 364-367.

[17] Pancha MO, Ngoufack Tsougmo JO, Sakinatou I, Velinga Ndolok AC, Tangyi Tamanji M. Prévalence, traitement et contrôle du diabète en milieu communautaire à Ngaoundere au Cameroun; Med et Sante Trop 2018; 28: 379-384. doi: 10.1684/mst.2018.0851.

[18] Mbouemboue OP, and Ngoufack TJO, High Blood Pressure Prevalence, Awareness, Control, and Associated Factors in Low-Resource African Setting 2019; Front. Cardiovasc 2019. Med. 6: 119. doi: 10.3389/fcvm.2019.00119.

[19] Dowd FJ. In xPharm: The Comphrensive Pharmacology Reference, 2007.

[20] Sodeman Jr, WA, Sodeman TC. in Instruction For Geriatric Patients (Third Edition), 2005.

[21] Abbott AV. Diagnostic Approach to Palpitations. American Family Physician. 2005; 71 (4), 743-750.

[22] Giada F, Raviele A. Diagnostic management of patients with palpitations of unknown origin. Italian Heart Journal. 2004; 5 (8), 581-586.

[23] Machihudé P, Yaovi A, Pessinaba S, Baragou S, N'djao J, Atta $\mathrm{B}$ et al. Epidemiology and etiologies of heart failure in Lomé. The Pan African Medical Journal. 2014; 18: 183. doi: 10.11604/pamj.2014;18.183.3983.

[24] Ikama MS, Kiimbally-Kaky, Gombet T, Ellenga-Mbolla BF, Dilou Bassemouka L. Mongo-Ngamani et al. Heart failure in elderly subjects in Brazzaville: clinical, etiological and evolutionary aspects. Med Trop. 2008; 68, 257-260.

[25] Onwuchekwa AC, Asekomeh GE. Pattern of heart failure in a Nigerian teaching hospital. Vascular Health and Risk Management. 2009; 5745-750.

[26] Damacesno BM, Mayosi M, Sani M, Ogah OS, Mondo, Dike $\mathrm{C}$, et al. The causes, treatment, and outcome of heart failure in 1006 africans from 9 countries Arch Inter Med 1722012 $1386-1394$. 